\title{
THE REMOTE PROGNOSIS OF EMPYEMA IN CHILDREN.
}

\author{
BY \\ J. M. SMELLIE, M.D., M.R.C.P. \\ (From the Children's Hospital, Birmingham.)
}

The immediate prognosis of empyema in children has been shown by Cameron and Osman(3) to depend entirely upon whether it is syn-pneumonic or meta-pneumonic. The former should not be operated upon by the removal of a rib and with an anæsthetic until the termination of the pneumonic process. The latter, on the other hand, may be submitted to operation at once.

The best surgical procedure for dealing with this disease is the subject of constantly recurring discussion, (4) (5) (8) (1) but the ultimate prognosis does not appear to have received the attention it warrants.

The term " cured" when applied to an empyema after operation seems a very wide one. It is exceptional to find any case discharged from hospital as otherwise. It seems that only such as have a persistent discharge from the wound, or failure of expansion of the lung, or other similar severe disability are not so regarded.

The only reference I have been able to find to the remote effects of this disease after operation is an investigation of 146 cases by Saltzman and Sievers ${ }^{(7)}$. Their patients had been operated upon between 20 and 40 years previously. These observers limited their attention to the increase of life insurance risk and the question of the subsequent development of tuberculosis. Their series showed a moderately increased mortality rate, mainly limited to cases between 19 and 25 years of age at the time of operation, but the tuberculosis death rate did not show any increase over that of the whole country. The analysis was made on information received.

My attention was first drawn to this question by encountering one or two cases with severe pulmonary disability consequent upon a previous operation for empyema. This it was which led me to conduct the following enquiry.

During 1913, 1914 and 1915, 71 cases of empyema were discharged as cured, after operation, from the Children's Hospital, Birmingham. As the average duration of the symptoms of these children before operation was $4 \cdot 8$ weeks, the shortest being two weeks, they may all be classified as of meta-pneumonic type. In all rib resection was the operative procedure adopted, and the stay in hospital after operation averaged 6.2 weeks. Fifty-three of these children have been traced during the past few months, and I have personally examined 36 of them. 
My observations are based on this series.

Regarding in the first place those 17 that have not been seen, definite information has been obtained from 12 that their health is and has been satisfactory in every way. One child has spent nearly two years in a sanatorium suffering from tuberculosis of the hip joint, apparently without any pulmonary lesion. The remaining four children have died-one from scarlet fever, but the cause in the other three could not be ascertained; one dying a few months, one 12 months, and one two years after operation.

The mortality rate, therefore, taking into consideration only those cases traced, is $7.5 \%$. Further, in none of these can the empyema definitely be blamed as the cause of death.

As stated above, 36 children have personally been examined at an interval of from 10 to 12 years after an operation for empyema. The youngest of these was one year and two months at the time of operation, and the large majority (viz. 22) were under 4 years of age.

The excellent state of the general physical conclition of these children has been an outstanding feature. In fact, in only three was the physique in any way below average. Another remarkable fact that has emerged from this investigation has been the almost complete immunity from respiratory diseases these children have enjoyed, none having afterwards suffered from asthma, pneumonia or another empyema, etc., and only a minority from coughs and colds.

No child subsequently developing pulmonary tuberculosis has been found. Three cases, it is true, have spent a short period in a sanatorium; one for six weeks in 1915, one for six weeks in 1918, and one for three months in 1923. My examination of these three did not reveal any evidence of tuberculous infection, the physique was good, there were no symptoms and the physical signs of fibrosis were of minor extent and of basal situation. Moreover, the clinical findings were supported by the radiological appearances. Probably these children were admitted to a sanatorium for observation; if the suspected diagnosis had been confirmed they would certainly have been detained for considerably longer periods.

Most writers on this subject record a certain number of cases in which a second operation has been found necessary, either for a discharging sinus or for a necrotic rib. Brown ${ }^{(2)}$ found $10.5 \%$ in 171 cases, and Pybus ${ }^{(6)}$ had $7 \%$ in 100 cases requiring such further treatment. There were two cases $(3.8 \%)$ in my series.

One child had its first operation for a left empyema in 1911. The wound broke down and 18 months later, in 1913, she was re-admitted to hospital and a second operation performed. She then remained well for two years wheil discharge again recurred. A third operation was performed in 1915, since when there has been no further trouble. When I saw the girl 14 years after the first operation and 10 years after the last, now aged 15 years, she 
looked well but pale. The left side of the chest measured an inch less than the right, but its expansion was almost as much as that of the right. There was clinical evidence of local fibrosis around the scar, but nothing further. The heart was not displaced, and she had no scoliosis.

The other case was another girl first operated upon in 1914 for a right sicied empyema. From 1915 to 1923 there was a constant discharge from the wound. During the latter year she was re-admitted to hospital and a second operation successfully performed. She is now a fine strong healthy looking girl ; the right shoulder was carried at a lower level than the left and the right chest measured three quarters of an inch less than the left and had practically no lateral expansion. There were signs of diffuse bronchitis throughout both lungs, but no bronchiolectasis and no scoliosis. A remarkable result in view of the fact that she had had a constant discharge for eight years.

Two further cases related some delay in the healing of the wound or some further discharge. In both the information was vague, medical attention was not necessary, and both showed but slight fibrosis though, in addition, some lateral curvature of the spine.

That so serious an intra-thoracic lesion as an empyema should heal to leave behind no trace of its occurrence is difficult to comprehend. Yet, in $25 \%$ (nine) of my cases the only physical signs remaining were those of the slightest fibrosis confined to the immediate neighbourhood of the scar, there was no deformity of the chest wall, no spinal curvature and the two sides of the chest were of equal measurement at expiration and at inspiration. Though the remaining $75 \%$ all showed some deviation from the normal, the degree of change was much less than would be expected. The two sides of the thorax were of equal measurement at rest in four cases, but there was a limitation of expansion of the affected side. In a further six cases, whilst the measurement of the two sides of the chest was unequal on expiration, the affected side showed as good an expansion as the healthy one.

Thoracic deformity in combination with a deficient expansion on the side of the operation was noted in 12 cases $(33.3 \%)$. These inequalities, however, were only of very slight extent. In seven the difference in measurement at expiration was under an inch, and the maximum difference of one and a half inches was present in only two cases. The diminution of expansion of the affected lung in all was very small, and in the majority could not have been detected without the aid of a measuring tape.

No child gave any symptoms or showed any physical signs to warrant a diagnosis of bronchiectasis or bronchiolectasis of even the mildest degree.

Radiological examinations of the chest were carried out in every case. These merely served to confirm the clinical findings. Practically every case showed some increase in hilum shadows, usually but not always more marked in the affected lung. In addition a few showed a limitation of movement of the homolateral side of the diaphragm. 
The examination of 36 children 10 to 13 years after operation for an empyema leads me to the opinion that the remote prognosis is excellent, though the number is much too small to permit of more than a provisional judgment. All show some evidence of scarring of the lung, but it is of negligible extent. So far as I have been able to determine, there is no factor which will enable any forecast of the degree of this fibrosis to be made. The duration of the disease prior to operation gives no assistance, nor does the time required after operation for the healing of the wound; in fact, the average duration of symptoms before operation and the subsequent stay in hospital of my group showing no clinical fibrosis was practically identical with those averages obtained from the whole 36 cases. To quote the extreme case, this was a boy who had had pneumonia 10 weeks before admission to hospital, he was kept 11 weeks after operation and yet recovery has, to all intents and purposes, been perfect.

I am indebted to Mr. F. A. R. Stammers for his kind assistance in collecting these cases, and I have to thank Dr. G. A. Auden for tracing some of the children.

\section{REFERENCES.}

1. British Medical Journ., Discussion: 1925, ii., 331.

2. Brown, H. P. : Ann. Surg. Phil., 1923, 1xxvli., 401.

3. Cameron, H. C., and Osman, A. A. : Lancet, 1923, i., 1097.

4. Ladd, W. E., and Cutler, G. D. : Am. Journ. Child. Dis. Chic., 1921, xxi., 547.

5. Poynton, F. J., and Reynolds, F. N. : Lancet, 1921, ii., 1100.

6. Pybus, F. C. : Practitioner, 1921, cvii., 238.

7. Saltzman, F., and Sievers, O.: Acta Chir. Scand., Stockholm, 1925, 1viii., 158.

8. Spence, R. C. : Am. Journ. Child. Dis. Chic. : 1920, xx., 545. 